\title{
Social Capital in Online Temporary Organizations: Addressing Critical, Complex Tasks through Deliberation
}

\author{
Elisabeth Joyce \\ Edinboro University of Pennsylvania \\ ejoyce@edinboro.edu
}

\author{
Pinar Ozturk \\ Duquesne University \\ ozturkp@duq.edu
}

\author{
Jacqueline C. Pike \\ Duquesne University \\ pikej@duq.edu
}

\begin{abstract}
Temporary organizations-small, task-focused, time-bound, agile groups - exist in mass collaborations to address tasks outside of existing procedures. Given that mass collaborations are informal and voluntary, this study explores the impact of social network attributes (cohesion and diversity) in temporary organizations on task completion. We suggest that participants' prior shared experience and demonstrated knowledge of the larger organization in online temporary organizations, traits of cohesion, and working less often with the same people, evidence of diversity, lead to greater likelihood of successful task completion. Contrary to predictions, however, the less consistent the participant contributions, the lower the likelihood of successful task completion.
\end{abstract}

\section{Introduction}

In the world known as Web 2.0, groups of individuals, either individually or collaboratively, work to shape information available on the Internet by creating, editing, and curating content. This work is carried out in online collaborations formed around a goal or purpose, and it is supported by a variety of technological platforms, such as wikis, social networking sites, and blogs.

The creation of content has been heralded [3] as the focus of researchers. To date, we have greater knowledge regarding how online organizations function, encourage participation, address challenges, grow, and even eventually disband [4]. Online collaborations have grown to staggering sizes. For example, over 135,000 registered users edited Wikipedia over a recent 30 -day period in addition to unregistered users, and Twitter, one of the largest platforms, reports 330 million active users globally.

A vast amount of work is being organized and performed within online collaborations. Within these large organizations, critical tasks arise that require closer attention. While organizations create policies, procedures, and routines to function efficiently and deliberate consistently, it is not possible to create a governance that addresses all possible scenarios. Thus, at times, the lack of an existing process or ambiguity in a policy needs to be hashed out to address the often nuanced, complex tasks that arise. This is especially relevant in mass collaborations that encompass high volumes of productivity and people alongside extraordinary turnover [8], leading to new participants with unique skillsets constantly entering and exiting the organization without necessarily having awareness of each other.

One method for responding to a critical, non-routine task is to form a smaller taskforce within the larger organization. Usually small taskforces exist for a specified time and then dissolve, allowing them to devote attention to the task without detracting from the concerns of the larger organization. Focusing on a "project" can also create fluidity and enact change in complex environments [10]. With their nonroutine, uncharted tasks, defined termination, and often heterogenous team composition, these smaller organizations can be viewed as temporary organizations [12]. A temporary organization is defined in a meta review [15] as "a temporally bounded group of interdependent organizational actors, formed to complete a complex task." Temporary organizations often form around a shared cause [16] and focus on the completion of a non-routine task [15, 18] or project [20]. They usually exist within a larger organization [18], but often retain a high level of autonomy from that organization [12, 15, 18]. Hallmarks of temporary organizations include predefined time to work and extermination upon completion of the task [22]. Further, a variety of experts often form a temporary organization, working together and bringing a variety of perspectives, given their different roles in the larger organization [24].

Temporary organizations can be created when the focal task is complex [18] and time-dependent. The larger organization may recognize that established governance is inadequate to address the complexity of the task or time-completion pressures and thus establish the temporary organization. When faced with limited guidance from formal policies and routines, individuals may shift towards greater reliance on informal social exchanges and less formal organizing methods. Temporary organizations in online collaborations face 
the extra pressures of high turnover, velocity, etc., given that all interaction takes place via the technological platform. Subsequently, online temporary organizations would seem to be facing an unsurmountable scenario a high-risk, complex task, a newly-formed team of strangers, and time constraints.

Thus, we seek to understand the impact of social capital on the success of online temporary organizations. Despite their limitations, online temporary organizations have the potential to be more than just temporary as they exist within a complex web of network relationships which can be mobilized to perform project tasks and direct essential resources [10, 29]. Further, online temporary organizations may become more utilized than ever before as organizations face the need for remote work [30].

\section{Deliberations in Mass Collaborations}

In mass collaborations, large numbers of individuals, often voluntarily, work collectively towards a common goal. The work is governed by a set of rules and procedures [31] in an attempt to manage the high volume and pace of the work. Based on their experience within the mass collaboration, individuals gain expertise in specific areas. While mass collaborations can produce quality products [32], they can also be areas of conflict [33] and detrimental behavior [34].

One focal area of research has been the deliberations about content to be removed from mass collaborations. Deciding whether to include or exclude content produced by the collaborators is a critical task that aids in maintaining integrity and quality. Research has focused on what types of content is removed from the community, finding that content is removed when it lacks importance or is obscure [13, 14], and on the participants in the deliberations, finding that individuals take on social roles in the deliberations and often become "regulars" in this space [13, 21, 23]. A robust research area has focused on the deliberations directly, finding that expression of expertise via policy citation and use of community-oriented terminology and logical rationales to be more beneficial $[1,2,9]$. See first row in Table 1 for summary.

\subsection{Temporary Organizations}

Temporary organizations have been studied in a range of contexts, from film crews [24], jails and mental hospitals [35, 36], to project management [37] and design teams [38]. Commonly, they are groups of individuals developed either within an organization or with the cooperation of multiple organizations to complete very specific tasks $[12,15]$ in a short time frame $[22,39]$. Most often, participating members enter a temporary organization to fulfill a particular role [15, 24]. On a film crew, for example, team members might be composed of a camera operator, a gaffer, a grip, and a director, among others.

Oversight of a temporary organization by a larger organization varies, with some acting completely autonomously $[12,35]$ and others closely linked to a greater organization by way of organizational identification [18], connection to the greater organization's network [15], or dependency on the greater organization for support or relationships [40].

Coordination of the temporary organization teams might be supported by the roles, described above, through an understanding of normative [41] or citizenship behavior [22] or through what has been termed, the development of "swift trust" [42]. Often, temporary organizations need to find their way through a specific task through active negotiation [43] and communication [44]. Temporary organizations are most frequently established to address situations that are nonroutine [18], very particular in nature [22] or more complex in scope [24]. Given the greater uncertainty of these problems, organizations can carve them out of the larger organization to protect it from destabilization and devote a small team's focused attention to address them.

\subsection{Deliberations in Mass Collaborations as Temporary Organizations}

Inevitably, despite extensive policies and procedures, an organization will at times face the need to address a critical task. Oftentimes these tasks involve deliberations among the participants, providing an opportunity for experts and involved participants to weigh in. To address critical tasks that arise, mass collaborations utilize temporary organizations in the online environment. As participation in mass collaborations is voluntary, participation in the temporary organization is thus voluntary as well. Sometimes known as "flash organizations" [45], these "emergent groups" [46] have their own identities and are structured like organizations [45] for greater ability to handle complex tasks. Examples of temporary organizations in mass collaboration include robotic control [47], data clustering [48], and galaxy labeling [49]. Specifically, in regard to deliberations in mass collaboration, prior research has highlighted attributes of these deliberations that correspond to attributes of temporary organizations, including their focus on critical tasks, inclusion of experts, ad-hoc formation, autonomy from the larger organization, and time constraint. For a summary of these points, see the second row of Table 1.

\section{Social Capital in Online Temporary}




\section{Organizations}

Social capital refers to the benefits derived through social networks [50]. In an organization, who people know, who they interact with, and how much and how often they interact influences how well the goals of the institution are met. Though online temporary organizations are autonomous from the larger organization, there is still coordination and communication across the formed temporary organizations and within each as well. Faced with a time constraint and complex tasks, participants in an online temporary organization focused on a deliberation can draw upon the resources available within the group in the form of the participants' social network and past experiences. Social capital in temporary organizations can increase knowledge integration, producing in turn higher levels of performance $[10,51]$. Social capital can increase trust [52], reduce conflict [51], and increase group effectiveness [10]. To measure the effectiveness of online temporary organizations, we focus on successful task completion. An online temporary organization is formed to address a complex task under a time constraint. Thus, if the task is successfully completed, the online temporary organization itself was successful, and vice versa.

To examine social capital in online temporary organizations and its effect on task completion, we first examine two aspects of social networks: cohesion and diversity.

Table 1. Mass collaboration curation deliberation literature

\begin{tabular}{|c|c|}
\hline 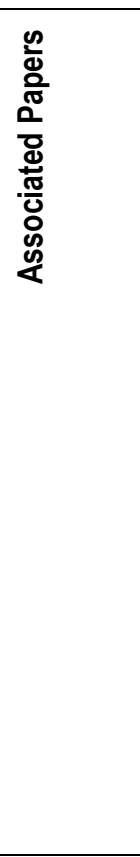 & 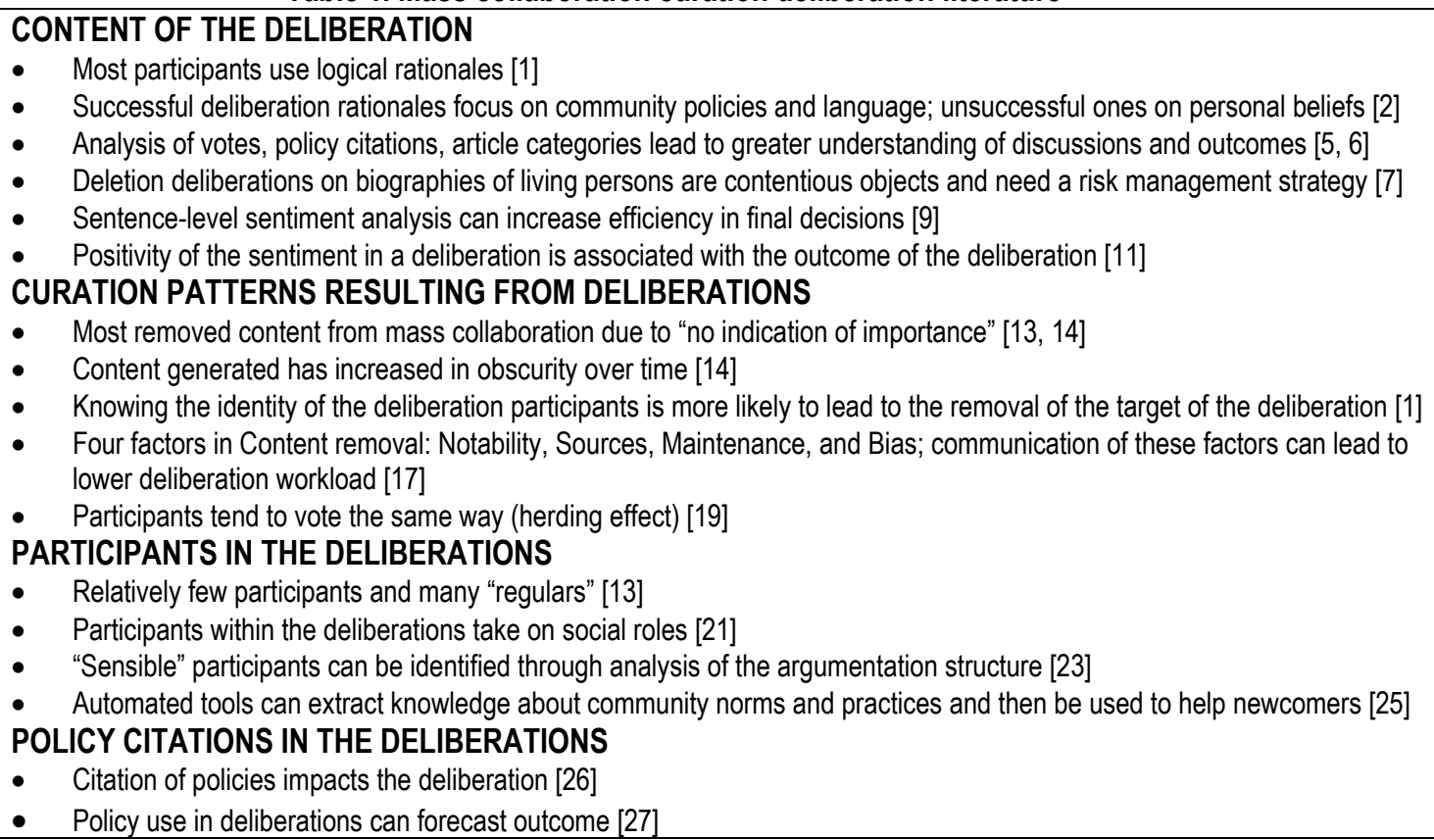 \\
\hline 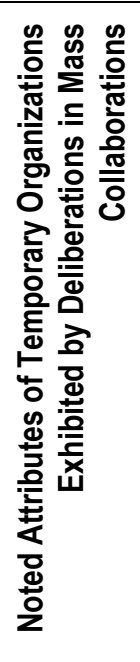 & $\begin{array}{l}\text { CRITICAL TASK } \\
\text { - } \quad \text { Deletion is a point of friction" and is controversial [17, 28] } \\
\text { - Deletion process impacts content generated by the mass collaboration [17] } \\
\text { - } \quad \text { Deletion process handles special projects that focus on risk management [7] } \\
\text { EXPERTISE OF PARTICIPANTS } \\
\text { - Understanding and knowledge of policies and guidelines is necessary [6] } \\
\text { - Deletion discussions' main participants include a small number of highly experienced editors [13] } \\
\text { - } \quad \text { mix of newcomers and experts formulate the best decisions [14] } \\
\text { FORMATION } \\
\text { - "Ad-hoc online task groups" [2] } \\
\text { - Naturally formed groups and recruited participants [14] } \\
\text { AUTONOMY } \\
\text { - Editors voice their opinions freely [1, 17, 28] } \\
\text { TIME CONSTRAINT } \\
\text { - Time-limited task [2, 26] } \\
\text { - "Seven days of open discussion" [13] }\end{array}$ \\
\hline
\end{tabular}




\subsection{Cohesion}

Social networks exhibit cohesion when they are relatively closed. Within the network, participants will likely know each other or have contact with each other. A cohesive network shows a high proportion of ties between the nodes, or participants, in a network [53]. Cohesive networks lead to greater shared knowledge [54], coordination [55], cooperation, and trust [50] among their participants, as the participants have familiarity with each other. In an online temporary organization, social networks can also be identified by their cohesion. However, the point of contact would be through previous work with another participant, or a prior pairing. Working on a critical task together as part of a previously formed online temporary organization could breed familiarity and trust, and repeated occurrences increase the likelihood of this occurring. Thus, we examine the cohesion of the social network in an online temporary organization by observing participants' prior shared participation experience. Prior shared experience is a signal of close contact, trust, and greater likelihood of being familiar with each other, which we suggest will increase the likelihood of success task completion in a temporary organization [46].

H1. The greater the shared participation experience among participants, the greater the likelihood of successful task completion by the online temporary organization.

Social networks also exhibit cohesion through references to a common set of knowledge [56], which can engender cooperation and trust and signals the citer's allegiance to the greater organization [15]. In an online temporary organization, a common set of knowledge is knowledge regarding the larger organization. Demonstrating knowledge of the larger organization can thus be a mechanism for stimulating cooperation among the participants in the online temporary organization.

To demonstrate knowledge of the larger organization, participants can reference fundamental principles of the larger organization and conduct themselves in accordance with organizational norms. The fundamental principles and organizational norms are often instantiated in the organization's governance structure. Thus, we examine the cohesion of the social network in an online temporary organization by observing participants' governance citation practices. Governance citation in a temporary organization, as a signal of cohesion, will increase the likelihood of successful task completion as it signals participants' loyalty to the greater organization [15].
H2. The greater the citation of the larger organization's governance structure in the online temporary organization, the greater the likelihood of successful task completion by the temporary organization.

\subsection{Diversity}

However, there is some concern that a social network can become too cohesive and thus too inwardly directed. This could lead to a lack of new information, limited awareness of those outside the organization, and overly strong weddedness to normal processes, leading to challenges when faced with difficult tasks or innovations [57]. Studies have shown that "structural holes" can address the stultification of the overly cohesive network by bringing a diversity of knowledge and voices into the field $[57,58]$.

Cohesion can be beneficial for setting up a group that communicates well and has established trust, but it can cause stagnation, circulating the same knowledge repeatedly. Diversity added to cohesion makes it so that new knowledge and new skillsets can interact with solid trust and information sharing to promote greater innovation. In other words, trust can be engendered when prior pairs work together, but new participants should be introduced as well, so that the same pairs are not continuously rehashing the same ideas.

As previously discussed, the point of contact in an online temporary organization is previous work with another participant, or a prior pair. While the existence of prior pairs can lead to greater cooperation, when the same pairs are consistently pairing up across temporary organizations to the exclusion of new pairs, the risk of knowledge stagnation increases. A temporary organization that exhibits diversity through the frequent intermixing of participants with outsiders will benefit. Thus, we examine the diversity of the social network in an online temporary organization by observing the frequency of shared participation experience. Specifically, we suggest that lower frequency of shared participation among participants (i.e., weak ties [59]) will increase the likelihood of successful task completion in the temporary organization. Lower frequency of shared participation among participants in the temporary organization demonstrates that outsiders are being woven into temporary organizations, adding fresh ideas and solutions.

H3. The lower the frequency of shared participation experience in a temporary organization, the greater the likelihood of successful task completion by the temporary organization. 
Equally important to the success of temporary organizations is the ability of participants to adapt to each task the organizations face. Online temporary organizations face new, uncharted problems to solve and group members that may or may not have prior shared experiences or common knowledge. Thus, it is imperative for the participants to demonstrate open mindedness and flexibility. In an online temporary organization, participants who are flexible will have demonstrated high entropy during prior related experiences, and thus would demonstrate high entropy in prior temporary organizations. Entropy can be examined by looking at the inconsistency in participant contributions. If participants' past contribution are consistent and similar, less flexibility is exhibited; whereas if participants past contributions are inconsistent and diverse, greater flexibility is exhibited.

H4. The greater the inconsistency in participant contributions in the online temporary organization, the greater the likelihood of successful task completion by the temporary organization.

\section{Methods}

\subsection{Context}

The mass collaboration selected for this study is the online encyclopedia Wikipedia. Wikipedia is a mass collaboration because it has as its single goal the creation and maintenance of numerous (well over five million articles), which are written and edited by groups of people working together. With over 35 million registered users, Wikipedia must organize, curate, and manage the development of thousands of new articles each month on top of existing content. Wikipedia remains an outlier in mass collaborations because of its enormous size but also because of its persistence in self- government. All of its governance systems, including its procedures and policies, have been developed by volunteer editors [31], but, while mass collaborations like Wikipedia have a lot of routine tasks to perform that are guided by policies and guidelines, these policies and guidelines cannot cover every possible scenario, so many tasks arise that are of a non-routine nature.

The context for the online temporary organization for the study is Wikipedia's Articles for Deletion (AfD) deliberations. Just as a library needs to regularly cull its collection of books that are out-of-date or of poor quality, Wikipedia continually reviews its articles for quality or appropriateness for inclusion in the encyclopedia, a critical task of content curation. There are mechanisms for deleting an article without an AfD deliberation, but when the deliberation is needed, a defined process is executed: an editor (any editor) proposes the article for deletion and states the reasons for this action; other editors have seven days within which to vote or comment on the article's merits; at the close of the allotted time, a Wikipedia administrator reviews the deliberation and determines the article's fate. Editors are encouraged to buttress their rationales with citations to appropriate Wikipedia policies, procedures, and guidelines.

AfD deliberations are focal temporary organizations because they are time-bound $[2,13,26]$, task-based, and semi-autonomous $[1,17,28]$ groups that carry out online deliberative tasks specifically identified by the larger organization as complex and critical [7, 17, 28]. AfD deliberations are also temporary organizations because they include participants with specific and limited role designations, such as the nominator, the decision-maker, and the editors who rely on their expertise and knowledge of the Wikipedia space for their deliberations $[6,13,14]$. Many AfD deliberations are closed sooner than the week-long span, called "Speedy Deletion," as the tasks posed to the group are straightforward, but there are a number that represent

Table 2. Measure descriptions

\begin{tabular}{|c|c|c|}
\hline Construct & $\begin{array}{l}\text { Related } \\
\text { Hypothesis }\end{array}$ & Measurement Description \\
\hline Deliberation Success & DV & $\begin{array}{l}\text { Success of the target AfD deliberation determined by whether consensus was reached } \\
\text { regarding the outcome ( } 0=\text { Unsuccessful, } 1=\text { Successful) }\end{array}$ \\
\hline Shared Participation Experience & $\mathrm{H} 1$ & $\begin{array}{l}\text { Count of pairs of participants within the target AfD who voted on the same AfD prior to the } \\
\text { start of the target AfD }\end{array}$ \\
\hline Governance Citation & $\mathrm{H} 2$ & $\begin{array}{l}\text { Count of occurrences of a citation to a Wikipedia Process, Policy, or Guidelines within the } \\
\text { target AfD }\end{array}$ \\
\hline $\begin{array}{l}\text { Frequency of Shared } \\
\text { Participation Experience }\end{array}$ & $\mathrm{H} 3$ & $\begin{array}{l}\text { Count of occurrences of two voting participants in the target AfD voting on the same AfD } \\
\text { prior to the start of the target AfD }\end{array}$ \\
\hline $\begin{array}{l}\text { Inconsistency in Participant } \\
\text { Contributions }\end{array}$ & $\mathrm{H} 4$ & $\begin{array}{l}\text { Average voting entropy among AfD participants based on voting histories between } \\
01 / 01 / 2016 \text { and the start of the target AfD; higher values } \rightarrow \text { greater inconsistency in voting }\end{array}$ \\
\hline Vote Count & Control & Count of contributions in the form of votes in the target AfD \\
\hline Comment Count & Control & Count of contributions in the form of comments in the target AfD \\
\hline Average Comment Word Count & Control & Average number of words used in the comments of the target AfD \\
\hline Avg. Vote Rationale Word Count & Control & Average number of words used in the vote rationales of the target AfD \\
\hline
\end{tabular}


much more complex tasks outside of the scope of specific policy, involving uncertainty and ambiguity, and requiring the full attention of the temporary organization $[7,17,28]$. These deliberative groups may arise out of the context of mass collaboration, but research has established their standing as "online task groups," if ad-hoc [2, 4].

\subsection{Data and Measures}

For this study we used the dataset developed by Mayfield and Black [27] on Wikipedia Articles for Deletion and drew all AfD deliberations from 2018 $(n=18606) .1066$ of those AfD deliberations were specified as "Speedy Deletion" cases in which administrators have broad consensus to bypass deletion discussion and immediately delete Wikipedia articles. Since the tasks temporary organizations undertake need to be specifically identified as complex, we deleted the speedy deletion AfD deliberations from our dataset and conducted our analysis on the rest of AfD deliberations $(\mathrm{n}=17540)$.

The dependent variable, Deliberation Success, was developed by dividing possible outcomes for AfD deliberations into conclusive outcomes, such as Keep or Delete (Deliberation Success $=1$ ), and inconclusive ones, such as No consensus (Deliberation Success $=0$ ), based on prior studies [60].

Cohesion was measured with two independent variables: Shared Participation Experience and Governance Citation. Shared participation experience measures past participation with other editors in the AfD deliberation between the start of 2016 and the target AfD from 2018. Governance citation counts the number of times Wikipedia process, policies, and guidelines were cited in the AfD deliberation. Diversity was measured by Frequency of Shared Participation and Inconsistency in Participant Contributions. Frequency of shared participation among participants is the number of instances of the editors working together prior to the target $\mathrm{AfD}$, and inconsistency in participant contributions measures the degree to which editors had not voted consistently in prior deliberations. Four control variables were also measured: the number of votes, number of comments, average number of words used in the comments and average number of words used in the vote rationales in the AfD deliberation. For a summary of the measures, see Table 2. For descriptive statistics and correlation table, see Table 3.

\section{Analysis and Results}

The analysis was conducted using Python (version 3.7) data libraries, such as Pandas, NumPy, SciPy and Sci-kit Learn. Due to the binary dependent variable, the data was analyzed using logistic regression with a classification decision threshold of 0.5. Since logistic regression chooses the class that has the biggest probability, in the case of 2 classes ( 0 (no success) vs. 1 (success)), if the threshold is 0.5 , then a probability of $\mathrm{P}(\mathrm{Y}=1)>0.5$ would mean that $\mathrm{P}(\mathrm{Y}=1)>\mathrm{P}(\mathrm{Y}=0)$.

$\mathrm{H} 1$ predicted that deliberation success is more likely when editors with previous experience with each other are working in the AfD deliberation. The analysis supported this prediction $(b=0.0028, p<0.001)$. H2 predicted that deliberation success is more likely when editors demonstrate their knowledge in regard to the larger organization. The analysis did not support this prediction $(b=0.0072)$. H3 predicted that deliberation success is more likely the less that editors worked together before. The analysis supported this prediction $(b=-0.0798, p<0.001)$. H4 predicted that the less consistently editors voted in previous AfDs, the greater the likelihood of deliberation success. The analysis did not support this prediction $(b=-0.2014)$. The results are summarized in Table 4.

Table 4. Regression models

\begin{tabular}{|c|c|c|}
\hline Variables & & Logit \\
\hline Intercept & & $4.0284^{* \star *}$ \\
\hline Comment Count & \multirow{4}{*}{ Controls } & $-0.0390^{* \star *}$ \\
\hline Vote Count & & $-0.0709^{* * *}$ \\
\hline Avg. Comment Word Count & & $-0.0064^{* * *}$ \\
\hline Avg. Vote Rationale Word Ct. & & $-0.0126^{* * *}$ \\
\hline
\end{tabular}

Table 3. Descriptive Statistics and Correlations

\begin{tabular}{|c|c|c|c|c|c|c|c|c|c|c|c|c|}
\hline & {$[\mathrm{A}]$} & {$[\mathrm{B}]$} & {$[C]$} & [D] & [E] & {$[\mathrm{F}]$} & [G] & {$[\mathrm{H}]$} & Mean & Std. Dev. & Min & Max \\
\hline Shared Participation Exp. [A] & 1 & & & & & & & & 15.42 & 46.77 & 0 & 2926 \\
\hline Governance Citation [B] & 0.5 & 1 & & & & & & & 2.61 & 3.71 & 0 & 95 \\
\hline $\begin{array}{l}\text { Frequency of Shared } \\
\text { Participation Exp. [C] }\end{array}$ & 0.08 & 0.3 & 1 & & & & & & 1.56 & 1.48 & 0 & 38 \\
\hline $\begin{array}{l}\text { Voting Inconsistency of } \\
\text { Participants [D] } \\
\end{array}$ & 0.03 & 0.01 & 0.08 & 1 & & & & & 0.50 & 0.18 & 0 & 1 \\
\hline Vote Count [E] & 0.7 & 0.6 & 0.6 & 0.09 & 1 & & & & 4.05 & 3.49 & 2 & 91 \\
\hline Comment Count [F] & 0.6 & 0.6 & 0.6 & 0.06 & 0.7 & 1 & & & 2.54 & 5.62 & 0 & 138 \\
\hline Avg. Comment Word Ct. [G] & 0.1 & 0.2 & 0.2 & 0.06 & 0.2 & 0.3 & 1 & & 32.49 & 41.41 & 0 & 593 \\
\hline $\begin{array}{l}\text { Avg. Vote Rationale Word Ct. } \\
{[\mathrm{H}]}\end{array}$ & 0.1 & 0.2 & 0.2 & 0.07 & 0.2 & 0.3 & 0.3 & 1 & 33.18 & 24.39 & 1 & 417 \\
\hline
\end{tabular}




\begin{tabular}{|l|l|l|}
\hline Shared Participation Exp. & H1 & $0.0028^{* * *}$ \\
\hline Governance Citation & H2 & 0.0072 \\
\hline Freq. of Shared Experience & H3 & $-0.0798^{* * *}$ \\
\hline Inconsistency in Participant & H4 & -0.2014 \\
Contributions & & \\
\hline${ }^{* * *}: p<0.001$ & & No. of obs. $=$ \\
${ }^{* *}: p<0.01$ & & 17539 \\
${ }^{*}: p<0.05$ & & $\mathrm{R}^{2}=7.8 \%$ \\
\hline
\end{tabular}

\section{Post-Hoc Analysis}

Binary classification can be challenging when the class distribution in the response variable of the dataset is imbalanced. For a binary response variable with two classes, when the event of interest (e.g., AfD Deliberation Success $=0$ ) is underrepresented, it is referred to as the minority class. When the class distribution is too skewed, classifiers tend to favor the majority class (see [61] for a survey of the domain), assigning the most frequent label to most test samples. Thus, it is difficult to get a meaningful and good predictive model due to lack of information for learning about the minority class. For example, in our dataset, $\sim 93 \%$ of the AfD deliberations have a successful outcome (count=16345; Deliberation Success $=1$ ), which means if a naïve classifier always assigns the majority label (i.e., successful) to any AfD deliberation, it will give an overall accuracy of more than $90 \%$ but without recovering any unsuccessful AfD (count=1194; Deliberation Success $=0$ ), which is not satisfying.

Table 5. Logistic regression using imbalanced dataset

\begin{tabular}{|c|c|c|c|}
\hline & precision & recall & f1-score \\
\hline 0 (no success) & 0.40 & 0.02 & 0.05 \\
\hline 1 (success) & 0.93 & 1.00 & 0.96 \\
\hline accuracy & 0.93 & \\
\hline
\end{tabular}

Data resampling has proven to be very effective for dealing with class-imbalance [61, 62]. Data resampling can be done by either downsizing the majority class through discarding instances, an approach known as undersampling, or by adding new samples to the minority class, which is known as oversampling.

The first approach, undersampling, may lead to underfitting as the majority class instances are randomly discarded and, thus, meaningful examples may be lost. Oversampling can be performed by simply replicating the existing elements of the minority class on the training set, but this strategy is known to be prone to overfitting [63]. To avoid this risk, the new samples can be created artificially by respecting the distribution of the minority class. One such approach is the Synthetic Minority Over-sampling Technique (SMOTE) [64].

Using SMOTE, we oversampled the minority class in our training data (AfD Deliberation Success $=0)$ and transformed it to include new synthetic examples in the minority class. We trained and tested a logistic regression model using our newly transformed training data. Our classification model results indicate that we can predict whether an AfD deliberation will have a successful or unsuccessful outcome with $\sim 70 \%$ accuracy. While our overall accuracy score is lower than the logistic regression model on the imbalanced dataset, looking at the precision and recall measures of our new model, we see that both successful and unsuccessful AfDs can be identified with similar precision and recall (see Tables 5 and 6).

Table 6. Logistic regression using balanced dataset

\begin{tabular}{|c|c|c|c|}
\hline & precision & recall & f1-score \\
\hline 0 (no success) & 0.72 & 0.64 & 0.68 \\
\hline 1 (success) & 0.67 & 0.74 & 0.71 \\
\hline accuracy & 0.70 & \multicolumn{3}{|l}{} \\
\hline
\end{tabular}

The logistic regression model from this transformed data set provides different results from that of the imbalanced data. H1 predicted that Deliberation Success is more likely when editors with previous experience are working with other editors in the AfD. The analysis supported this prediction $(b=0.0024, p<$ $0.001)$. H2 predicted that Deliberation Success is more likely when editors demonstrate their knowledge of the external organization. The analysis supported this prediction $(b=0.0362, p<0.001)$. H3 predicted that Deliberation Success is more likely the less that editors had worked together before. The analysis supported this prediction $(b=-0.1981, p<0.001)$. H4 predicted that the less consistently that editors had voted in previous AfDs, the greater the likelihood of Deliberation Success. The analysis did not support this prediction $(b$ $=-0.5084, p<0.001)$. See Table 7 for these results and Table 8 for a complete list of hypotheses and results.

Table 7. Regression models

\begin{tabular}{|c|c|c|}
\hline Variables & & $\begin{array}{l}\text { Logit with } \\
\text { Oversampled } \\
\text { Data }\end{array}$ \\
\hline Intercept & & $1.9558^{* * *}$ \\
\hline Comment Count & \multirow{4}{*}{ Controls } & $-0.0664^{* * *}$ \\
\hline Vote Count & & $-0.0646^{* * * t}$ \\
\hline Avg. Comment Word Ct. & & $-0.0087^{* * *}$ \\
\hline Avg. Vote Rationale Word Ct. & & $-0.0150^{\text {t*t }}$ \\
\hline Shared Participation Exp. & $H 1$ & $0.0024^{* * t}$ \\
\hline Governance Citation & H2 & $0.0362^{* * t}$ \\
\hline Frequency of Shared Exp. & $\mathrm{H3}$ & $-0.1981^{* * *}$ \\
\hline $\begin{array}{l}\text { Inconsistency in Participant } \\
\text { Contributions }\end{array}$ & H4 & $-0.5084^{* * *}$ \\
\hline $\begin{array}{l}* * * 0<0.001 \\
:: p<0.01 \\
:: p<0.05\end{array}$ & & $\begin{array}{l}\text { No. of obs. }= \\
21913 \\
R^{2}=14.5 \%\end{array}$ \\
\hline
\end{tabular}


The coefficients in the regression models show the estimated effect of the independent variables on the success of AfDs in log odds, or logit. Since interpreting the results in terms of probability and understanding their effect size would be easier, we can convert estimated log odds to odds by taking exp(logit), and calculating probability as odds/(1+odds). The coefficient of the intercept in our model shows us the baseline probability of an AfD being successful, which is $87.54 \%$ in our dataset. One unit increase in Shared Participation Experience increases that probability by $1.38 \%$ to $88.92 \%$, while all other variables remain zero. One unit increase in Governance citation increases the probability of AfD success by $1.42 \%$ and one unit increase in Frequency of Shared Experience decreases the probability of AfD success by $1.42 \%$. While our fourth hypothesis is not supported, the effect of Inconsistency in Participant Contributions is significant but in the opposite direction than hypothesized. One unit increase in Inconsistency in Participant Contributions decreases the probability of AfD success by $1.01 \%$.

Table 8. Supported hypotheses

\begin{tabular}{|l|l|l|}
\hline Construct & Analysis & PostHoc \\
\hline H1: Shared Part. Exp. & Supported & Supported \\
\hline H2: Governance Citation & Unsupported & Supported \\
\hline H3: Freq. Shared Part. Exp. & Supported & Supported \\
\hline $\begin{array}{l}\text { H4: Inconsistency in Part. } \\
\text { Contributions }\end{array}$ & Unsupported & Unsupported \\
\hline
\end{tabular}

\section{Discussion}

This study demonstrates that cohesion and diversity function to support the success of deliberations in this mass collaboration temporary organization. If editors worked previously with other editors in the AfD, it was more likely to conclude successfully, showing that cohesion, the trust and comfort of working with others who are known, operates in the temporary organization. In addition, the less frequently editors previously worked with other editors (distant dyadic relationships or weak ties), the more likely the temporary organization concluded successfully, showing that diversity in the temporary organization, that is, editors who are not closely tied to one's own network, is associated with better outcomes.

Post-hoc analysis results show that there is a relationship between participants' knowledge of the greater organization, demonstrating their affiliation with it, and successful goal attainment in temporary organizations.

The more consistent the votes of editors were in previous deliberations, the greater the likelihood of success in the current deliberation. Given the particular context of this study in Wikipedia, that editors who vote consistently, no matter the context of the particular AfD, might be what the community terms "Inclusionists" or "Exclusionists," that is, editors who are affiliated with subgroups in Wikipedia with mandates to work to keep or delete articles as a matter of principle. However, it may also be that editors who vote more consistently the same way engender greater trust by others on the team.

These results suggest several practical implications for online communities facing complex tasks. It is clear, for instance, that lengthier deliberations, in terms of word count, are associated with less success. To reduce word expenditure and raise success probability, it might serve the organization to introduce very defined roles, like with a film crew, so that each participant enters the deliberation as the "facilitator," "negotiator," "conflict mediator," etc. Likewise, greater support for newcomers in the form of direction to the governance system might induce participants to rely more on it sooner, raising the likelihood of a successful temporary organization. Referencing the governance system encourages newcomers, increasing diversity, but also shows them how to utilize the common set of knowledge, increasing cohesion.

\section{Limitations and Future work}

The main limitation of the data was the imbalance between successful and unsuccessful deliberations. It is a good sign of the health of Wikipedia that most of its AfD deliberations conclude appropriately, but in order to study those that do not, an examination of the deliberations in the full dataset would be in order. The cross-sectional nature of our analysis (i.e., AfD deliberations only from 2018) also affect r-squared and effect sizes of our variables. While low r-squared and effect sizes are common in Social Sciences due to uncertainty in human behavior and dynamics [65], future studies can build upon and expand current research to full $\mathrm{AfD}$ deliberations. In addition, future work should develop greater understanding of the complete network of AfDs for better and clearer measures of range and cohesion. Future work should also take advantage of the text of the AfDs, such as to conduct sentiment analysis to tease out more social capital influence that might be operating in these deliberations.

\section{Conclusion}

Given the current situation of the pandemic, where groups of people need to work together in remote conditions to solve complex and gnarly tasks, this work provides some clarity about features of temporary organizations that lead to better outcomes. Cohesion, in 
particular, is clearly essential. Having had previous experience with people also makes successful goal attainment more likely.

\section{References}

[1] L. Xiao and N. Askin, "What influences online deliberation? A Wikipedia study," Journal of the Association for Information Science and Technology, vol. 65, pp. 898-910, 2014.

[2] J. Schneider, K. Samp, A. Passant, and S. Decker, "Argument about deletion: How experience improves the acceptibility of arguments in ad-hoc online task groups," presented at the CSCW'13, San Antonio, TX, 2013.

[3] D. Tapscott and F. Williams, Wikinomics: How mass collaboration changes everything. New York, NY: Portfolio, 2008.

[4] M. Zamiri and L. M. Camarinha-Matos, "Organizational structure for mass collaboration and learning," in Doctoral Conference on Computing, Electrical and Industrial Systems, 2019, pp. 14-23.

[5] B. S. Gelley and T. Suel, "Automated decision support for human tasks in a collaborative system: the case of deletion in Wikipedia," in Proceedings of the 9th International Symposium on Open Collaboration, 2013, pp. 1-12.

[6] A. Javanmardi and L. Xiao, "What's in the Content of Wikipedia's Article for Deletion Discussions?," in Companion Proceedings of The 2019 World Wide Web Conference, 2019, pp. 1215-1223.

[7] E. Joyce, B. Butler, and J. Pike, "Handling flammable materials: Wikipedia biographies of living persons as contentious objects," in Proceedings of the 2011 iConference, 2011, pp. 25-32.

[8] S. Ransbotham and G. C. J. Kane, "Membership Turnover and Collaboration Success in Online Communities: Explaining Rises and Falls from Grace in Wikipedia," MIS Quarterly, vol. 35, pp. 613-627, September 2011.

[9] W. Mao, L. Xiao, and R. Mercer, "The use of text similarity and sentiment analysis to examine rationales in the large-scale online deliberations," in Proceedings of the 5th Workshop on Computational Approaches to Subjectivity, Sentiment and Social Media Analysis, 2014, pp. 147-153.

[10]F. Di Vincenzo and D. Mascia, "Social capital in projectbased organizations: Its role, structure, and impact on project performance," International Journal of Project Management, vol. 30, pp. 5-14, 2012.

[11]L. Xiao and N. Sitaula, "Sentiments in Wikipedia Articles for Deletion Discussions," in International Conference on Information, 2018, pp. 81-86.

[12]R. A. Lundin and A. Soderholm, "A theory of the temporary organization," Scandinavian Journal of Management, vol. 11, pp. 437-455, 1995.

[13]R. S. Geiger and H. Ford, "Participation in Wikipedia's article deletion process," in WikiSym '11, Mountain View, CA, 2011, pp. 201-202.

[14]S. K. Lam and J. Riedl, "Is Wikipedia growing a longer tail?," in GROUP'09, Sanibel Island, FL, 2009.
[15]C. M. Burke and M. J. Morley, "On temporary organizations: A review, synthesis and research agenda," Human Relations, vol. 69, pp. 1235-1258, 2016.

[16]J. Packendorff, "Inquiring into the temporary organization: New directions for project management research," Scandinavian Journal of Management, vol. 11, pp. 319-333, 1995.

[17]J. Schneider, A. Passant, and S. Decker, "Deletion discussions in Wikipedia: Decision factors and outcomes," in 8th Annual International Symposium on Wikis and Open Collaboration, 2012, pp. 1-10.

[18]X. Ding, Q. Li, H. Zhang, Z. Sheng, and Z. Wang, "Linking transformational leadership and work outcomes in temporary organizations: A social identity approach," International Journal of Project Management, vol. 35, pp. 543-556, 2017.

[19]D. Taraborelli and G. L. Ciampaglia, "Beyond notability. Collective deliberation on content inclusion in Wikipedia," in 2010 Fourth IEEE International Conference on SelfAdaptive and Self-Organizing Systems Workshop, 2010, pp. 122-125.

[20]T. K. Gustavsson and A. Hallin, "Goal seeking and goal oriented projects: Trajectories of the temporary organization," International Journal of Managing Projects in Business, vol. 8, pp. 368-378, 2015.

[21] S. Jain, A. Bhatia, A. Rein, and E. H. Hovy, "A Corpus of Participant Roles in Contentious Discussions," in LREC, 2014, pp. 1751-1756.

[22]T. Braun, A. I. Ferreira, and J. Sydow, "Citizenship behavior and effectiveness in temporary organizations," International Journal of Project Management, vol. 31, pp. 862-876, 2013.

[23]S. Jain, "Identifying sensible participants in online discussions," 2016, pp. 41-47.

[24]B. A. Bechky, "Gaffers, Gofers, and Grips: Role-Based Coordination in Temporary Organizations," Organization Science, vol. 17, pp. 3-21, 2006.

[25]L. Xiao and J. Nickerson, "Imperatives in Past Online Discussions: Another Helpful Source for Community Newcomers?," in Proceedings of the 52nd HICSS, 2019.

[26] E. Joyce, J. C. Pike, and B. S. Butler, "Rules and roles vs. consensus: Self-governed deliberative mass collaboration bureaucracies," American Behavioral Scientist, vol. 57, pp. 576-594, 2013.

[27]E. Mayfield and A. W. Black, "Analyzing Wikipedia deletion debates with a group-decision-making forecast model," in CSCW, 2019.

[28]J. A. Schneider and K. Samp, "Alternative interfaces for deletion discussions in Wikipedia: Some proposals using decision factors," in 8th Annual International Symposium on Wikis and Open Collaboration, WikiSym 2012, 2012.

[29] J. Sydow and U. Staber, "The institutional embeddedness of project networks: The case of content production in German television.," Regional Studies, vol. 36, pp. 215227, 2002.

[30]M. Hart. (2020, July 15, 2020). Remote work after the pandemic. Journal of Accountancy. Available: https://www.journalofaccountancy.com/news/2020/jul/re mote-work-after-coronavirus-pandemic.html

[31]B. Butler, E. Joyce, and J. Pike, "Don't look now, but we've created a bureaucracy: The nature and roles of 
policies and rules in Wikipedia," in $\mathrm{CHI}$ '08, Florence, Italy, 2008, pp. 1101-1110.

[32] J. Giles, "Internet encyclopedias go head to head," Nature, vol. 438, pp. 900-901, 2005.

[33]O. Arazy, L. Yeo, and O. Nov, "Stay on the Wikipedia task: When task-related disagreements slip into personal and procedural conflicts," Journal of the American Society for Information Science and Technology, vol. 64, pp. 1634-1648, 2013.

[34] S. Kiesler, R. E. Kraut, P. Resnick, and A. Kittur, "Regulating behavior in online communities," in Building successful online communities: Evidence-based social design, R. E. Kraut and P. Resnick, Eds., Cambridge: MIT Press, 2021, pp. 125-178.

[35] E. Goffman, Encounters: Two studies in the Sociology of interaction. Indianapolis, IN: Bobbs-Merrill, 1961.

[36] E. Goffman, Asylums. Garden City, NY: Anchor Books, 1961.

[37] M. Ebers and I. Maurer, "To continue or not to continue? Drivers of recurrent partnering in temporary organizations," Organization Science, vol. 37, pp. 18611895, 2016.

[38]P. Badke-Schaub, A. Neumann, K. Lauche, and S. Mohammed, "Mental models in design teams: A valid approach to performance in design collaboration?," CoDesign, vol. 3, pp. 5-20, 2007.

[39] R. M. Bakker, R. DeFillippi, A. Schwab, and J. Sydow, "Temporary organizing: Promises, processes, problems," Organization Studies, vol. 37, pp. 1703-1719, 2016.

[40]C. Jensen, S. Johansson, and M. Lofstrom, "Policy implementation in the era of accelerating projectification: Synthesizing Matland's conflict-ambiguity model and research on temporary organizations," Public Policy and Administration, vol. 33, pp. 447-465, 2018.

[41] V. Smith, "New forms of work organization," Annual Review of Sociology, vol. 23, pp. 315-319, 1997.

[42] S. Christopherson and M. Storper, "The effects of flexible specialization on industrial politics and the labor market: The motion picture industry," Industrial Labor Relations Review, vol. 42, pp. 331-347, 1989.

[43] A. Strauss, L. Schatzman, D. Ehrlich, R. Bucher, and M. Sabshin, "The hospital and its negotiated order," in The hospital in modern society, E. Freidson, Ed., New York: Free Press, 1963, pp. 147-168.

[44]J. Liang, "Socializing collective identity in a temporary interorganizational collaboration," in International Communication Association, Prague, Czech Republic, 2018.

[45] M. A. Valentine, D. Retelny, A. To, N. Rahmati, T. Doshi, and M. S. Bernstein, "Flash organizations: Crowdsourcing complex work by structuring crowds as organizations," in CHI 2017, Denver, CO, 2017, pp. 3523-3537.

[46]A. Lanamäki and J. Lindman, "Before the sense of 'we': Identity work as a bridge from mass collaboration to group emergence," presented at the OpenSym '17, Galway, Ireland, 2017.

[47] W. S. Lasecki, K. I. Murray, S. White, R. C. Miller, and J. P. Bigham, "Real-time crowd control of existing interfaces," in UIST'11, Santa Barbara, CA, 2011, pp. 2332.
[48]L. B. Chilton, G. Little, D. Edge, D. S. Weld, and J. A. Landay, "Cascade: Crowdsourcing taxonomy creation," in CHI 2013, Paris, France, 2013, pp. 1999-2008.

[49]C. J. Lintott, K. Schawinski, A. Slosar, K. Land, S. Bamford, D. Thomas, et al., "Galaxy Zoo: Morphologies derived from visual inspection of galaxies from the Sloan Digital Sky Survey," Monthly Notices of the Royal Astronomical Society, vol. 389, pp. 1179-1189, 2008.

[50]J. S. Coleman, "Social capital in the creation of human capital," American Journal of Sociology, vol. 94, pp. S95S120, 1988.

[51]L. Zhan, N. Wang, X.-L. Shen, and Y. Sun, "Knowledge quality of collaborative editing in Wikipedia: An integrative perspective of social capital and team conflict," in PACIS, 2015, p. 171.

[52]D. Meyerson, K. E. Weick, and R. M. Kramer, "Swift trust and temporary groups," in Trust in organizations: Frontiers of theory and research, R. M. Kramer and T. R. Tyler, Eds., Thousand Oaks, CA: Sage Publications, 1996, pp. 166-195.

[53]M. Gargiulo, G. Ertug, and C. Galunic, "The two faces of control: Network closure and individual performance among knowledge workers," Administrative Science Quarterly, vol. 54, pp. 299-333, 2009.

[54]M. Granovetter, Getting a job: A study of contacts and careers. Cambridge, MA: Harvard University Press, 1974.

[55]R. Gulati and M. Gargiulo, "Where do interorganizational networks come from?," American Journal of Sociology, vol. 104, pp. 1439-93, 1999.

[56]O. Nov, C. Ye, and N. Kumar, "A social capital perspective on meta-knowledge contribution and social computing," Decision Support Systems, vol. 53, pp. 118126, 2012.

[57]R. S. Burt, "The contingent value of social capital," Administrative Science Quarterly, vol. 42, pp. 339-365, 1997.

[58]R. Reagans and E. W. Zuckerman, "Networks, diversity, and productivity: The social capital of corporate R\&D teams," Organization Science, vol. 12, pp. 502-517, 2001.

[59]M. S. Granovetter, "The strength of weak ties," in Social networks: Elsevier, 1977, pp. 347-367.

[60]J. Pike, E. Joyce, and B. Butler, "Overcoming transience and flux: Routines in community-governed mass collaborations," Internet Technology \& People, vol. 30, pp. 449-472, 2017.

[61]H. He and Y. Ma, Eds., Imbalanced learning: Foundations, algorithms, and applications. Wiley-IEEE, 2013.

[62]H. He and E. A. Garcia, "Learning from imbalanced data," IEEE Transactions on knowledge and data engineering, vol. 21, pp. 1263-1284, 2009.

[63] N. V. Chawla, N. Japkowicz, and A. Kotcz, "Special issue on learning from imbalanced data sets," ACM SIGKDD explorations newsletter, vol. 6, pp. 1-6, 2004.

[64]N. V. Chawla, K. W. Bowyer, L. O. Hall, and W. P. Kegelmeyer, "SMOTE: Synthetic minority over-sampling technique," Journal of artificial intelligence research, vol. 16, pp. 321-357, 2002.

[65]I. Newman and C. Newman, "A discussion of low rsquares: Concerns and uses," Educational research quarterly, vol. 24, p. 3, 2000. 